\title{
REVIEW
}

\section{Early and late effects of radiation treatment for prevention of coronary restenosis: a critical appraisal}

\author{
O F Bertrand, S Lehnert, R Mongrain, M G Bourassa
}

Radiation treatment represents a new and promising approach for prevention of restenosis after coronary intervention. ${ }^{12}$ Restenosis results from a complex interplay between thrombosis, vessel remodeling, and neointima formation. Although the exact contribution of each process is still debated, neointima formation has been shown to play a major role in humans after balloon angioplasty and more recently after stent implantation. It is now admitted that vessel shrinkage plays a predominant role in restenosis after catheter based coronary interventions, whereas in-stent restenosis seems exclusively caused by neointima formation. $^{3}{ }^{4}$ Neointima formation results mainly from the accumulation of proliferating smooth muscle cells (SMCs) and extracellular matrix (ECM) secretion. Adventitial myofibroblast proliferation and ECM deposition may also play a role in vessel shrinkage in a way similar to scar retraction after skin injury. ${ }^{5}$

Radiation treatment holds the promise to reduce or prevent SMC and myofibroblast proliferation and thus to interfere with vessel remodeling and neointima formation. There are currently two different approaches to deliver endovascular irradiation. One is based on $\gamma$ or $\beta$ sources which are positioned locally through a catheter, to deliver single doses at high dose rate in a limited period of time. The other uses radioactive stents for continuous low dose rate treatment. Both techniques have undergone extensive animal testing and initial pilot studies have confirmed the potential. However, in addition to cytoxicity, ionising radiations have a number of biological effects that complicate the prediction of an optimal dose for restenosis prevention. In this article, we apply fundamental concepts and recent findings in radiation biology to the interpretation of the early and late consequences of radiation treatment used for restenosis prevention.

\section{Cellular effects of radiation treatment}

Available data describing neointimal cell proliferation are mostly qualitative and relatively little is known about the absolute number of proliferating cells associated with human restenosis. The recruitment of quiescent cells into the proliferating pool seems to differ significantly among different animal models currently used to study the pathophysiology of restenosis. ${ }^{6}$ In humans, however, the extent of SMC proliferation varied from 1-25\% after vessel injury. ${ }^{7-9}$ It has also been shown that SMCs undergo only a few proliferation cycles before resuming a quiescent state. ${ }^{6}$ The volume associated with neointima formation after vessel injury is rather limited. Using arterial sections of human coronary vessels with restenosis, we found that the neointima area represented about $10 \%$ of the total vessel area. $^{10}$ In the Scripps trial, Teirstein and colleagues randomised 55 patients with restenosis or in-stent restenosis to either conventional treatment or endovascular radiation treatment with a ${ }^{192}$ Ir source. ${ }^{1}$ Results at six months were impressive with a $68 \%$ reduction in restenosis rate after irradiation. The initial clinical benefit seems to be maintained at two years. ${ }^{11}$ Using intravascular ultrasound imaging, they measured a mean (SD) in-stent neointimal growth volume of 45 (39) $\mathrm{mm}^{3}$ in the control group. After delivery of a mean dose of $8 \mathrm{~Gy}$ to the medial layer, neointimal growth volume was reduced to 16 (23) $\mathrm{mm}^{3}{ }^{3}$ Consequently, this suggests that a limited dose of radiation is indeed effective in reducing neointima formation.

Using different animal models, several investigators have shown that single doses in excess of 10 Gy significantly reduce neointima formation after balloon angioplasty or before stent implantation. ${ }^{2}$ These results have been observed after short term follow up (usually between two and four weeks), although persistent benefit at six months using ${ }^{192} \mathrm{Ir}$ has subsequently been reported. ${ }^{12} 13$ In humans, preliminary experience using prescribed doses from 8-25 Gy to the vessel wall have also shown positive early results with limited angiographic late loss. ${ }^{1415}$

The response of normal tissues to ionising radiation varies according to the type of cellular organisation. For some tissues, such as the skin, organisation is hierarchical with cells responsible for proliferation and function in separate compartments. A stem cell compartment consists of pluripotent clonogenic cells, which proliferate and sometimes mature into differentiating transit cells, ultimately losing 
their ability to divide and becoming functional cells of limited life span. Under normal conditions, there is equilibrium between cell proliferation and cell loss. The cellular effects of ionising radiation on this type of tissue are thus a direct result of the number of stem cells that are sterilised by radiation.

In contrast, coronary artery walls consist of three different layers which contain variable numbers of SMCs, fibroblasts, macrophages, and inflammatory cells, the inner part of the vascular wall being lined up by a monolayer of endothelial cells. These cells represent differentiated functional cells with a very long but finite lifetime. Under steady state conditions, fibroblastic, SMC, and endothelial cell proliferation in the vascular wall is extremely low but may increase in response to appropriate stimuli. These cells may retain latent injurythat is, irreversible DNA damage - for a long time until it is expressed at mitosis. One can assume that a dose of ionising radiation delivered at the time of vessel injury will affect several cell types. As a result of irreversible DNA damage, cells having received a lethal dose of radiation will die when they attempt to divide. This means, in the context of restenosis, that a significant number of proliferating cells will die early after the coronary intervention. It is possible, after high doses, that the rate of expression of the irreversible DNA damage could accelerate to the point where there would be an "avalanche" effect progressively amplifying the rate of cellular depletion. ${ }^{16}$ Later effects may thus originate from progressive cell depletion of the vascular wall resulting from delayed cell division. This ultimately could create significant wall thinning with the possibility of aneurysm development.

Aneurysm formation has already been shown in humans after endovascular irradiation. Condado and colleagues reported that four of 20 patients treated with a single dose of radiation developed coronary aneurysm after a mean follow up of two years. ${ }^{14}$ Waksman and colleagues reported the occurrence of a subclavian vein aneurysm after endovascular treatment with a ${ }^{192}$ Ir source,${ }^{17}$ and more recently in a peripheral artery (presented at Cardiovascular Radiation Therapy III, Washington, February 1999). In the European arm of the beta energy restenosis trial (BERT) using a $90 \mathrm{Sr} / \mathrm{Y}$ source, the Rotterdam group also noticed the emergence of a coronary aneurysm (P Serruys, personal communication, 1999). In contrast, cell death and medial thinning have also been described in atherosclerotic coronary arteries and yet coronary aneurysms are uncommon. ${ }^{18}$ These post irradiation aneurysms could also be the consequence of dissections, which have been prevented from complete healing by the radiation effects and, subsequently, enlarge as false aneurysms. Indeed, Meerkin and colleagues, using intravascular ultrasound imaging, found less dissection resolution after endovascular radiation treatment compared to a control group. ${ }^{19}$ In that context, endothelial regeneration appears critical in preventing cells of the vascular wall from entering the cell cycle and maintaining steady state conditions in the media and the adventitia. ${ }^{20}$ Intravascular ultrasound imaging may also help to differentiate between true and false aneurysms since their prognosis appears different. ${ }^{21}$

Waksman and colleagues showed a significant reduction in myofibroblastic proliferation in the adventitia of irradiated pig coronary arteries. ${ }^{22}$ On this basis, radiation treatment has been hypothesised to prevent negative vascular remodeling. This has also been suggested by recent intravascular ultrasound imaging of human coronary arteries six months after endovascular radiation treatment. These studies revealed little change in vessel dimensions, indicating that radiation treatment counteracts negative vessel remodeling early after coronary intervention. ${ }^{23}$

Besides cell death during mitosis, radiation treatment also induces apoptosis. ${ }^{24}$ Apoptotic cells have also been demonstrated after coronary balloon angioplasty and in human restenotic lesions. ${ }^{25}$ To date, however, endovascular radiation treatment has not been proved to increase apoptosis early after vessel injury, and its role in this process remains undefined. ${ }^{22}$

Not all radiation doses produce the desired effect. A number of animal studies have reported a delayed or increased neointima formation with lower doses. ${ }^{26}{ }^{27}$ Some investigators have also observed a beneficial effect at early follow up which was later lost. ${ }^{26}$ In the pilot trial performed at the Montreal Heart Institute using single prescribed doses between 12-16 Gy, one patient presented with a late restenosis at one year which was not present at the six month angiographic follow up. This recurrent stenosis was highly resistant and required cutting balloon angioplasty, which may suggest a fibrotic component. The emerging edge problem of restenosis occurring at the borders of the irradiated zones or at the extremities of a radioactive stent, the so called "candy wrapper effect", is also probably a manifestation of a low dose stimulatory effect. ${ }^{28}$ This apparent paradoxical effect deserves some attention. If sufficient clonogenic cells (with an intact potential to divide) survive radiation exposure, they can divide and repopulate the tissue. Cellular depletion below a critical level may also initiate an accelerated rate of proliferation resulting from an increase in the rate of stem cell division or recruitment of resting cells into the cell cycle. This process is well known to radiation oncologists as the response of certain tumours and normal tissues to fractionated irradiation. ${ }^{29}$ In the case of normal tissue such as the vascular system, this could explain delayed obstruction or border zone restenosis. ${ }^{30}$ It is likely that this process results also in part from growth factor release from intact or injured cells.

Gene regulation after radiation treatment Early and late gene induction have been well described after vessel injury. Early gene transcription produces regulatory DNA binding proteins which possess multiple roles. The transcription factors encoded by these genes are critically involved in the entry of the cell into the $G_{1}$ phase of the cell cycle (first phase 


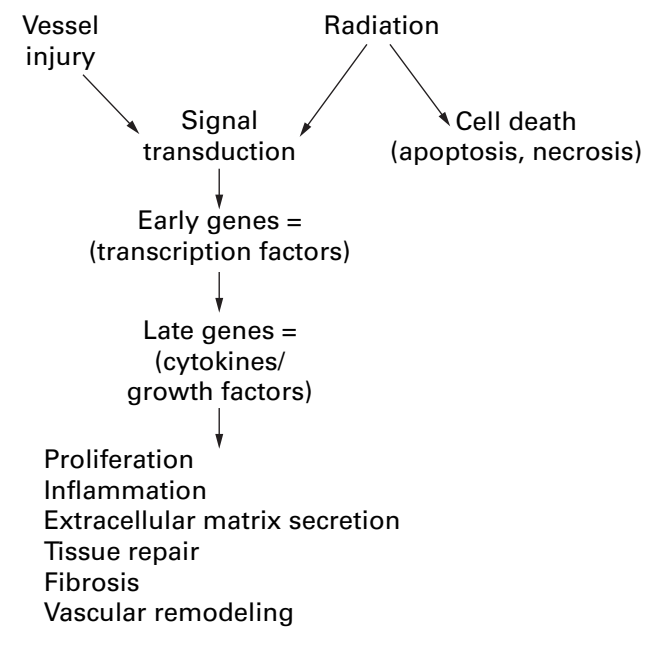

Figure 1 Pathways after vessel injury and radiation treatment. Note that the benefit of radiation treatment for restenosis prevention is dependent on the killing effect.

before DNA synthesis (S) and mitosis $\left(\mathrm{G}_{2}-\right.$ $\mathrm{M})$ ). In the basal state, most vascular cells are in the quiescent or $\mathrm{G}_{0}$ phase and some of these become activated soon after injury. In the rat carotid model, for instance, this corresponds with an entry into the cell cycle of $20-40 \%$ of medial SMCs in the 48 hours after balloon injury. ${ }^{6}$ Late gene induction promotes the expression and secretion of several cytokines, growth factors, and hormones. More than a decade of research has established the role of basic fibroblast growth factor (bFGF), platelet derived growth factor (PDGF), transforming growth factor $\beta$ (TGF $\beta$ ), insulin-like growth factor (IGF), and the interleukins in the inflammatory and growth processes leading to intimal thickening after vessel injury. ${ }^{31}$

Radiation treatment holds the promise to block the final effector of restenosis, namely proliferating SMCs and myofibroblasts. However, it has recently become apparent that the cellular response to damaging agents such as ionising radiation is also complex and involves many genes and multiple regulatory mechanisms. Radiation induces gene products particularly important to radiation response. First, transcription factors involved in DNA repair, and second, cytokines and growth factors which play a role in inflammation and in the late effects of radiation treatment. ${ }^{32}$ Thus gene induction after vessel injury shares some similarity with radiation response (fig 1). While little is known yet about gene induction after radiation treatment in the context of restenosis prevention, gene activation and cytokine/ growth factor release are likely to play a critical role in the overall effect of endovascular radiation treatment.

Among early response genes that code for transcription factors and are activated by vessel injury and irradiation, the regulation of p53 deserves special attention. After irradiation, intracellular p53 protein concentration is increased through post transcriptional mechanisms. ${ }^{33}$ p53 is critically involved in the activation of distinct pathways leading to cell cycle arrest, apoptosis, or both. ${ }^{34}$ p53 is indeed the most frequently mutated gene in human cancer and mutated p53 has been implicated in the cellular radiation response. Furthermore, a role for p53 in restenosis has been proposed recently. ${ }^{35}$ Apoptotic cells have been identified in atherosclerotic plaques and restenotic lesions and a link with p53 mutation has been postulated. ${ }^{36}$ Hannan and colleagues described increased radiosensitivity for fibroblasts cultured from patients with overt coronary atherosclerosis. ${ }^{37}$ The possibility that atherosclerosis induces genotypic modifications that will alter radiation response is a fascinating hypothesis that needs to be explored further.

Experimental data indicate that growth factors and cytokines are synthesised de novo and secreted by vascular cells which survive irradiation. Witte and colleagues exposed endothelial cells to single doses of ionising radiation and showed a dose related increase in growth factor activity identified as bFGF and PDGF related. ${ }^{38}$ Later, it was shown that bFGF through protein kinase $\mathrm{C}$ is implicated in the protection of endothelial cells against radiation induced apoptosis. ${ }^{39}$ Another cytokine, tumour necrosis factor $\alpha$ (TNF $\alpha)$ is also induced by ionising radiation and has been shown to sensitise cells to the lethal effects of irradiation. ${ }^{40}$ Thus, cytokines appear also to modulate the acute radiation response. This interaction could play a role, particularly after radioactive stent implantation and longer radiation exposure.

Normal human cell lines have also been shown, in response to radiation, to secrete factors which may influence the delayed response of the vascular system. Among others, TGF $\beta$ is released after irradiation exposure. ${ }^{41}$ Exploring radiation induced lung fibrosis, Rubin and colleagues described a biphasic release of TGF $\beta$ and PDGF which was correlated with the fibrogenic response..$^{42}$ In addition, they showed a similar time related phenomenon for several types of collagen and for fibronectin. ${ }^{42} \mathrm{Hehr}-$ lein and colleagues showed a dose related increase in collagen 1 deposition after radioactive stent implantation in rabbit iliac arteries. ${ }^{43}$ Interestingly, Rubin and colleagues described PDGF release after vessel injury in rat carotid arteries which was reduced in radiation treated animals. ${ }^{44}$ They also postulated that radiation could act by reducing the number of macrophages which are known to release several growth factors. ${ }^{44}$ Exposing SMCs to $\gamma$ irradiation, Martin and colleagues showed that there was an extensive accumulation of extracellular matrix containing elastin between the cell layers. ${ }^{45}$ Therefore, experimental data strongly suggest that irradiation of vascular cells may also induce profibrogenic cytokine synthesis and secretion, which in turn could produce abnormal cell proliferation and ECM secretion. Ultimately, these complex interactions may contribute to fibrosis formation. Some investigators have also described fibrosis, a well known consequence of external vascular irradiation, in the different vascular layers after endovascular radiation treatment for restenosis prevention. ${ }^{13} 46$

Therefore, it may be that if an optimal dose has been delivered after vessel injury, initial 


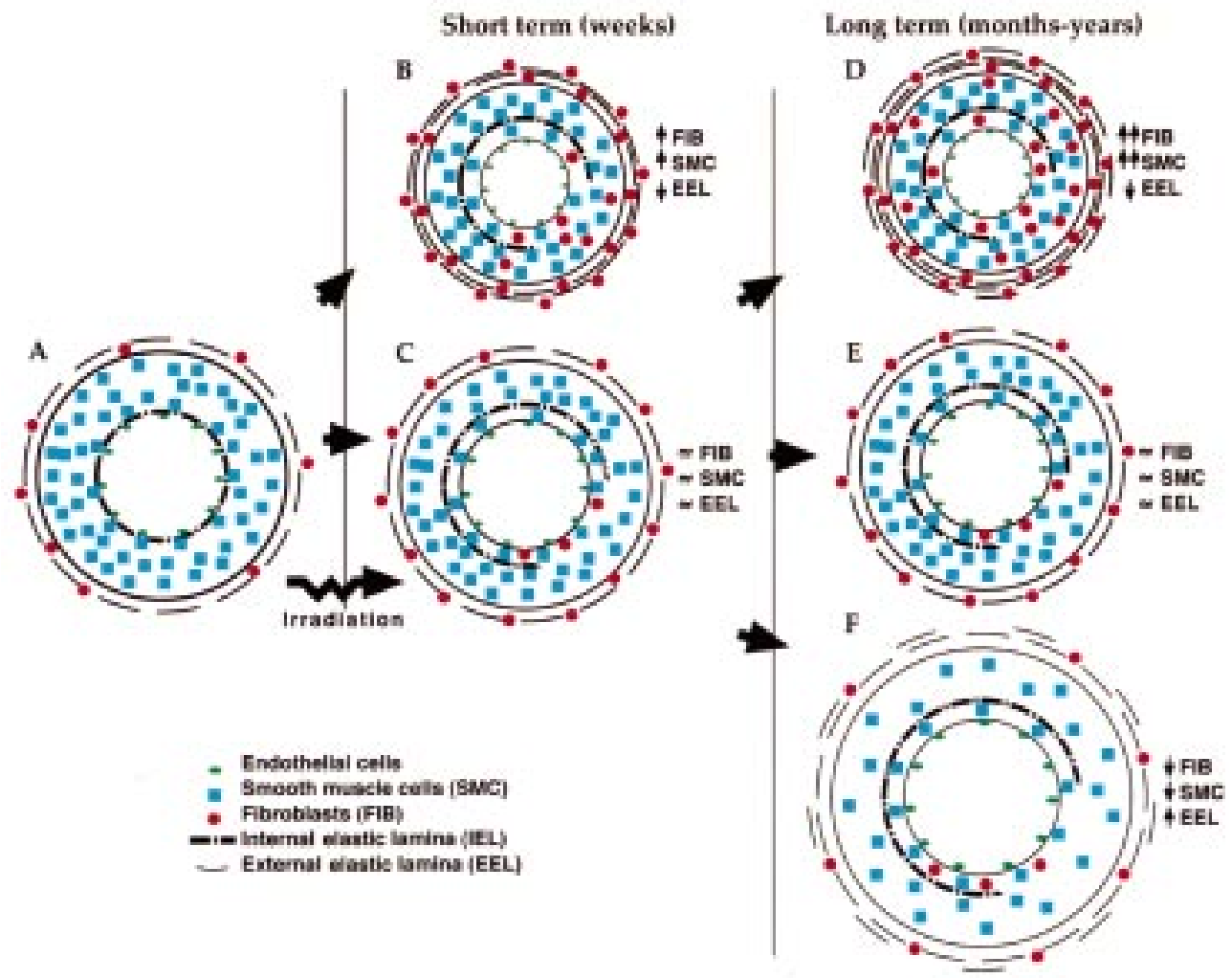

Figure 2 Hypothetical pathways after radiation treatment for restenosis prevention. (A) Normal vessel before injury. (B) Response to injury leads to restenosis by neointima formation and negative vessel remodeling. (C) Short term effect of radiation treatment. Neointima formation and vessel remodeling are limited. (D) Extended follow up with predominant fibrosis and increased cell proliferation. This may lead to a scarring effect with vessel shrinkage and further lumen obstruction. (E) Extended follow up with persistent benefit that is dependent on an optimal dose (therapeutic window). (F) Extended follow up with predominant cell depletion. This may lead to a reduction in cell density and exaggerated vessel enlargement (aneurysm).

positive effects of a significant reduction in neointima formation and absence of negative vessel remodeling will persist during long term follow up beyond two or three years. However, outside this presumed therapeutic window, at least two types of vessel remodeling are likely to occur (fig 2). First, if cell depletion is the predominant radiation effect, the irradiated vascular segment may progressively enlarge and the arterial wall become thinned and lead to aneurysm formation. Intravascular ultrasound imaging has an important role to play in differentiating these malformations into true or false aneurysms, as their respective prognosis appears different. Second, if fibrosis is predominant there is a potential risk of vascular wall thickening with negative remodeling and further lumen reduction. As discussed, serial intravascular ultrasound examinations of irradiated segments will provide new clues to assess potential late effects of endovascular radiation treatment. Stent implantation is also likely to influence delayed effects of radiation by preventing late vessel remodeling. ${ }^{1147}$ Indeed, no vessel wall aneurysm or delayed restenosis have been described so far in irradiated stented vessels.

\section{Summary}

Radiation treatment for restenosis prevention seems an attractive new approach to counteract the most vexing problem for interventional cardiologists since the introduction of balloon

angioplasty. Early clinical results have confirmed impressive short term experimental data and there is some evidence to suggest that endovascular radiation treatment will have a therapeutic window for restenosis prevention. Dose finding clinical trials and long term follow up studies are clearly required to establish better the therapeutic benefit. However, it is likely that limitations will continue to emerge with accumulating experience and long term follow up. In particular, we propose that the cytokine cascade model postulated in both restenosis and radiation induced fibrosis may explain some early adverse results and long term side effects of radiation treatment when used for prevention of restenosis. ${ }^{42} 48$

Olivier F Bertrand is supported by the Fonds de la Recherche en Santé du Québec (FRSQ). Part of this work has also been supported by Medtronic Inc, Minneapolis, USA, and by Draximage Inc, Montreal, Canada.

1 Teirstein P, Massulo V, Jani S, et al. Catheter-based radiotherapy to inhibit restenosis after coronary stenting. $N$ Engl f Med 1997;336:1697-703.

2 Bertrand OF, Mongrain R, Lehnert S, et al. Intravascular radiation therapy in atherosclerotic disease: promises and premises. Eur Heart f 1997;18:1385-95.

3 Mintz GS, Popma JJ, Pichard AD, et al. Arterial remodeling after coronary angioplasty: a serial intravascular ultrasound study. Circulation 1996;94:35-43.

4 Hoffman R, Mintz GS, Dussaillant GR, et al. Patterns and mechanisms of in-stent restenosis. A serial intravascular ultrasound study. Circulation 1996;94:1247-54.

5 Shi Y, Pieniek M, Fard A, et al. Adventitial remodeling after coronary arterial remodeling. Circulation 1996;93:340-8.

6 Clowes AW, Reidy MA, Clowes MM. Kinetics of cellular proliferation after arterial injury: smooth muscle growth in the absence of endothelium. Lab Invest 1983;49:327-33. 
7 O'Brien E, Alpers C, Stewart D, et al. Proliferation in primary and restenotic coronary atherectomy tissue: implications $223-31$.

8 Pickering J, Weir L, Jakanowski L, et al. Proliferative activity in peripheral and coronary atherosclerotic plaque among patients undergoing percutaneous revascularization. $\mathcal{F}$ Clin Invest 1993;91:1469-72.

9 Kearney M, Pieczek A, Haley L, et al. Histopathology of in-stent restenosis in patients with peripheral artery disease. Circulation 1997;95:1998-2002.

10 Bertrand OF, Brunette J, Mongrain R, et al. Histomorphology of coronary restenosis in humans. Relevance for radiation therapy. In: Waksman R, ed. Cardiovascular radiation therapy III. Washington: Cardiology Research Foundation 1999:66.

11 Teirstein PS, Massulo V, Jani S, et al. Two-year follow-up after catheter-based radiotherapy to inhibit coronary after catheter-based radiotherapy
restenosis. Circulation 1999;99:243-7.

12 Waksman R, Robinson KA, Croker IR, et al. Endovascular low-dose irradiation inhibits neointima formation after coronary artery balloon injury in swine. Circulation coronary artery

13 Wiedermann JG, Marboe C, Amols H, et al. Intracoronary irradiation markedly reduces neointimal proliferation afte balloon angioplasty in swine: persistent benefit at 6-month follow-up. $\mathcal{F} \mathrm{Am}$ Coll Cardiol 1995;25:1451-6.

14 Condado JA, Waksman R, Gurdiel O, et al. Long-term angiographic and clinical outcome after percutaneous transluminal coronary angioplasty and intracoronary radiation therapy in humans. Circulation 1997;96:727-32.

15 King SB, Williams DO, Chougoule L, et al. Endovascular beta-radiation to reduce restenosis after coronary balloon angioplasty: results of the beta energy restenosis tria (BERT). Circulation 1998;97:2025-30.

16 Nias AH. An introduction to radiobiology. New York: John Wiley, 1990

17 Waksman R, Robinson KA, Croker IR, et al. Long term efficacy and safety of endovascular low dose irradiation in a cacy and safety of endovascular low dose irradiation in a diol 1995;94:I-300.

18 Mitchinson JM, Hardwick SJ, Bennett MR. Cell death in atherosclerotic plaques. Curr Opin Lipid 1996;7:324-9.

19 Meerkin D, Bonan R, Bertrand OF, et al. Radiation effect on dissection resolution: an IVUS study. In: Waksman R, ed. Cardiovascular radiation therapy III. Washington: Cardiology Research Foundation 1999:64

20 Scott-Burden T, Vanhoutte PM. The endothelium as a regulator of vascular smooth muscle proliferation. Circulation 1993;87:V51-5.

21 Bertrand OF, Mongrain R, Soualmi L, et al. Development of coronary aneurysm after cutting balloon angioplasty: assesment by intracoronary ultrasound. Cathet Cardiozasc Diagn 1998;44:449-52.

22 Waksman R, Rodriguez JC, Robinson KA, et al. Effect of intravascular irradiation on cell proliferation, apoptosis, and vascular remodeling after balloon overstretch injury of porcine coronary arteries. Circulation stretch injury of

23 Meerkin D, Tardif JC, Crocker IR, et al. Effects of intracoronary $\beta$ radiation therapy after coronary angioplasty: an intravascular ultrasound study. Circulation 1999;99. 1660-5.

24 Dewey WC, Ling CC, Meyn RE. Radiation-induced apoptosis: relevance to radiotherapy. Int $\mathcal{F}$ Radiat Oncol Bio Phys 1995;33:781-96.

25 Isner J, Kearney M, Bortman S, et al. Apoptosis in human atherosclerosis and restenosis. Circulation 1995;91. 2703-11

26 Verin V, Popowski Y, Urban P, et al. Intra-arterial beta irradiation prevents neointimal hyperplasia in a hypercholesterolemic rabbit restenosis model. Circulation 1995;92. 2284-90.

27 Weinberger J, Amols $\mathrm{H}$, Ennis R, et al. Intracoronary irradiation: dose response for the prevention of restenosis in swine. Int f Radiat Oncol Biol Phys 1996;36:767-75.
28 Albiero R, Di Mario C, Gregorio JD, et al. Intravascular ultrasound (IVUS) analysis of beta-particle emitting radioactive stent implantation in human coronary arteries. Preiminary immediate and intermediate-term results of the MILAN study [abstract]. Circular

29 Dorr W, Emmendorfer H, Haide E, et al. Proliferation equivalent of accelerated repopulation in mouse oral mucosa. Int F Radiat Biol 1994;66:157-67.

30 Brenner D, Miller R, Hall E. The radiobiology of intravascular irradiation. Int F Radiat Oncol Bio Phys 1996; 36:805-10.

31 Libby P, Tanka H. The molecular bases of restenosis. Prog Cardiovasc Dis 1997;40:97-106.

32 Weichselbaum RR, Hallahan DE, Sukhatme V, et al. Biological consequence of gene regulation after ionizing radiation exposure. $\mathcal{F}$ Natl Cancer Inst 1991;83:480-4.

33 Bunz F, Dutriaux A, Lenganer C, et al. Requirement for P53 and P21 to sustain G2 arrest after DNA damage. Science 1998;282:1497-501.

34 Ko L, Prives C. p53: puzzle and paradigm. Genet Devel 1996;10:1054-72.

35 Speir E, Modali R, Huang E, et al. Potential role of human cytomegalovirus and p53 interaction in coronary resteno-

36 Bennett MR, Littlewood TD, Schwartz SM, et al. Increased sensitivity of human vascular smooth muscle cells from atherosclerotic plaques to p53-mediated apoptosis. Circ Res 1997;81:591-99.

37 Hannan M, Khougeer F, Halees Z, et al. Increased radiosensitivity and radioresistant DNA synthesis in cultured fibroblastsfrom patients with coronary atherosclerosis. Arterioscler Thromb 1994;14:1761-6.

38 Witte L, Fuks Z, Haimovitz-Freidman A, et al. Effects of radiation on the release of growth factors from cultured bovine porcine and human endothelial cells. Cancer Res 1989;489:5066-72.

39 Haimovitz-Friedman A, Balaban N, McLoughlin M, et al. Protein kinase $\mathrm{C}$ mediates basic fibroblast growth factor protection of endothelial cells against radiation-induced apoptosis. Cancer Res 1994;54:2591-7.

40 Hallahan DE, Spriggs DR, Beckett MA, et al. Increased tumor necrosis factor alpha mRNA after cellular exposure to ionizing radiation. Proc Natl Acad Sci USA 1989;86: $10104-7$.

41 Martin M, Lefaix JL, Pinton P, et al. Temporal modulation of TGF- $\beta 1$ and $\beta$-actin gene expression in pig skin and muscular fibrosis after ionizing radiation. Radiat Res 1993; 134:63-70.

42 Rubin P, Johnston CJ, Williams JP, et al. A perpetual cascade of cytokines postirradiation leads to pulmonary fibrosis. Int F Radiat Oncol Biol Phys 1995;33:99-109.

43 Hehrlein C, Gollan C, Dönges K, et al. Low-dose radioactive endovascular stents prevent smooth muscle cell proliferation and neointimal hyperplasia in rabbits. Circulation 1995; $92: 1570-5$.

44 Rubin P, Williams J, Riggs P, et al. Cellular and molecular mechanisms of radiation inhibition of restenosis. Part I:role of the macrophage and platelet-derived growth factor. Int 7 of the macrophage and platelet-derived grot
Radiat Oncol Biol Phys 1998;40:929-41.

45 Martin BM, Ritchie AR, Toselli P, et al. Elastin synthesis and accumulation in irradiated smooth muscle cell cultures. Connect Tissue Res 1992;28:181-9.

46 Mazur W, Ali M, Khan M, et al. High dose rate ntracoronary radiation for inhibition of neointimal formation in the stented and balloon-injured porcine models of restenosis: angiographic, morphometric, and histopatho-
logic analyses. Int $\mathcal{f}$ Radiat Oncol Biol Phys 1996;36:77788

47 Schopohl B, Liermann D, Pohlit L, et al. ${ }^{192} \mathrm{Ir}$ endovascular brachytherapy for avoidance of intimal hyperplasia after percutaneous transluminal angioplasty and stent implantaion in peripheral vessels: 6 years of experience. Int 7 Radiat Oncol Biol Phys 1996;36:835-40.

48 Libby P, Schwartz D, Brogi E, et al. A cascade model for restenosis, a special case of atherosclerosis progression. Circulation 1992;86:47-52. 